\title{
Validation of the 10-item Centre for Epidemiological Studies Depression Scale (CES-D-10) in Zulu, Xhosa and Afrikaans populations in South Africa
}

Emily Claire Baron ${ }^{1 *}$, Thandi Davies ${ }^{1}$ and Crick Lund ${ }^{1,2}$

\begin{abstract}
Background: The 10-item Centre for Epidemiological Studies Depression Scale (CES-D-10) is a depression screening tool that has been used in the South African National Income Dynamics Study (NIDS), a national household panel study. This screening tool has not yet been validated in South Africa. This study aimed to establish the reliability and validity of the CES-D-10 in Zulu, Xhosa and Afrikaans. The CES-D-10's psychometric properties were also compared to the Patient Health Questionnaire (PHQ-9), a depression screening tool already validated in South Africa.

Methods: Stratified random samples of Xhosa, Afrikaans and Zulu-speaking participants aged 15 years or older $(N=944)$ were recruited from Cape Town Metro and Ethekwini districts. Face-to-face interviews included socio-demographic questions, the CES-D-10, Patient Health Questionnaire (PHQ-9), and WHO Disability Assessment Schedule 2.0 (WHODAS). Major depression was determined using the Mini International Neuropsychiatric Interview. All instruments were translated and back-translated to English. Construct validity was examined using exploratory factor analysis with varimax rotation. Receiver Operating Characteristics (ROC) curves were used to investigate the CES-D-10 and PHQ-9's criterion validity, and compared using the DeLong method.

Results: Overall, 6.6, 18.0 and 6.9\% of the Zulu, Afrikaans and Xhosa samples were diagnosed with depression, respectively. The CES-D-10 had acceptable internal consistency across samples ( $\alpha=0.69-0.89)$, and adequate concurrent validity, when compared to the PHQ-9 and WHODAS. The CES-D-10 area under the Receiver Operator Characteristic curve was good to excellent: 0.81 (95\% Cl 0.71-0.90) for Zulu, 0.93 ( $95 \% \mathrm{Cl}$ 0.90-0.96) for Afrikaans, and 0. 94 (95\% Cl 0.89-0.99) for Xhosa. A cut-off of 12, 11 and 13 for Zulu, Afrikaans and Xhosa, respectively, generated the most balanced sensitivity, specificity and positive predictive value (Zulu: 71.4, 72.6\% and 16.1\%; Afrikaans: 84.6\%, 84.0\%, 53.7\%; Xhosa: 81.0\%, 95.0\%, 54.8\%). These were slightly higher than those generated for the PHQ-9. The CES-D-10 and PHQ-9 otherwise performed similarly across samples.
\end{abstract}

Conclusions: The CES-D-10 is a valid, reliable screening tool for depression in Zulu, Xhosa and coloured Afrikaans populations.

Keywords: Validation, Depression, CES-D-10, South Africa, Prevalence, PHQ-9, Screening

\footnotetext{
* Correspondence: emily.baron@uct.ac.za

'Alan J Flisher Centre for Public Mental Health, Department of Psychiatry and

Mental Health, University of Cape Town, Office 32, Building B, 46 Sawkins

Road, 7700 Rondebosch, Cape Town, South Africa

Full list of author information is available at the end of the article
} 


\section{Background}

Major depression is one of the leading causes of disease burden worldwide [1] and has clear economic implications [2, 3]. The South African Stress and Health (SASH) study, conducted between 2002 and 2004, investigated the national prevalence of mental disorders, and reported that nearly $10 \%$ of the population suffered from major depressive disorder at least once in their lifetime [4]. Yet, only one in four individuals with depression or anxiety receive treatment in South Africa [5].

Where mental health services are available, the use of indicated screening tools has been advocated as a way to detect individuals at risk of depression [6]. The timely identification of individuals displaying depressive symptoms is important, as it allows such individuals to be referred for mental health treatment services to prevent depressive symptoms from worsening into full clinical depression. The Centre for Epidemiological Studies Depression Scale (CES-D) is a 20-item screening tool, initially developed to detect depression in general populations [7]. It has been validated in a variety of settings, such as Zambia [8] and South Africa [9]. Subsequently, several shorter versions have been developed, including Andresen's 10-item version (CES-D-10), generated through item-total correlations with the original 20-item CES-D [10]. Originally validated in the older population [11, 12], the CES-D-10 has good psychometric properties in both healthy and psychiatric populations $[13,14]$, and in adolescents [15]. In Andresen's original study, a cut-off score of 8 or 10 on the CES-D-10 was identified as optimal to identify individuals at risk of depression. A few studies have since focused on the diagnostic validity of the CES-D-10, yet all were conducted in the United States or in China, and cutoffs varied considerably, from 8 to $16[11,13,14,16]$. The reliability and validity of the CES-D-10 has, however, never been investigated in South Africa.

The CES-D-10 has been used in the National Income Dynamics Study (NIDS), a South African national household panel study of 7300 households [17]. The study's first wave was conducted in 2008 and another three waves were conducted to date, one every two years. At each survey, a range of economic, health and wellbeing data were collected from all household members of 15 years of age or more. While a few studies from the first waves of NIDS used the CES-D-10 as a longitudinal measure of depression severity [18-20], most have used a cut-off of 10 to classify participants at high risk of depression, as suggested by Andresen [21-24].

The aim of this study was to determine the reliability and validity of the CES-D-10 in three major South African languages: Zulu, Xhosa and Afrikaans. The psychometric properties of the CES-D-10 were also compared to those of the Patient Health Questionnaire (PHQ-9) [25]; another common screening tool for depression, already validated in primary health care patients in North West Province and in Gauteng in South Africa [26, 27].

\section{Methods \\ Design}

This validation study investigated the internal consistency, concurrent, construct and criterion validity of the CES-D10 among Zulu, Xhosa and Afrikaans-speaking populations. These languages are the most commonly spoken in South Africa, according to the 2011 census [28]: 22.7\% of the South African population speaks Zulu, 16.0\% speaks Xhosa and $13.5 \%$ speaks Afrikaans. The study consisted of face-toface interviews which included (1) basic demographic and economic questions; (2) depression and functioning screening instruments; and (3) the Mini International Neuropsychiatric Interview (MINI) 6.0 (Major Depressive Episode) [29].

\section{Measures \\ Demographic and socio-economic information}

Basic demographic and socio-economic information covered age, gender, population group, marital status, education, employment status, personal income and assets owned. Household economic measures included type of dwelling, number of household members, as well as access to electricity, water and sanitation.

\section{Centre for Epidemiological Studies Depression Scale (CES-D-10)} The CES-D-10 is a 10-item Likert scale questionnaire assessing depressive symptoms in the past week [10]. It includes three items on depressed affect, five items on somatic symptoms, and two on positive affect. Options for each item range from "rarely or none of the time" (score of 0) to "all of the time" (score of 3). Scoring is reversed for items 5 and 8, which are positive affect statements. Total scores can range from 0 to 30 . Higher scores suggest greater severity of symptoms.

\section{Patient Health Questionnaire - 9 item (PHQ-9)}

The PHQ-9 is a 9-item screening measure for depression, where participants are asked to rate how often they were bothered by specific symptoms over the last two weeks [25]. Each item is scored from 0 ("Not at all") to 3 ("Nearly every day"). Higher scores indicate greater symptoms of depression. The PHQ-9 has been validated in a range of settings and populations in low and middle-income countries [30], including South Africa [26].

\section{Mini International Neuropsychiatric Interview (MINI) 6.0, Major Depressive Episode module}

The presence of major depression was determined using the MINI 6.0 [29], which uses the DSM-IV criteria for major depressive episodes. It has been used as a gold 
standard in many cross-cultural studies, including in HIV-positive patients in South Africa [31, 32].

\section{WHO Disability Assessment Schedule (WHODAS 2.0) (12-item)}

Functional impairment was assessed using the WHODAS 2.0 [33]. It comprises 12 items with response options ranging from 'No difficulty' to 'Extreme difficulty or unable to do'. The item-response-theory (IRT) based scoring was used, as set out in the WHODAS 2.0 Manual [34]: scores are percentages, with higher percentages suggesting greater impairment. The WHODAS 2.0 has undergone extensive validation, and has good reliability and validity across cultures and population groups [34].

All sections of the questionnaire, including the MINI assessment, were translated into Xhosa, Afrikaans and Zulu, and back translated to English, by six independent translators. The research team worked with the translators to assess the accuracy of each item, and to resolve discrepancies where these arose.

\section{Sample size}

Three samples were recruited, one for each language. Given that the prevalence of individuals screening $\geq 10$ or $\geq 15$ on the CES-D-10 in the first wave of NIDS was 28 and $8 \%$ respectively in the Western Cape, and 32 and $5 \%$ in KwaZulu Natal, ${ }^{1}$ it was determined that a total of 300 participants per sample would be sufficient to analyse higher CES-D-10 scores, and have enough power to assess criterion validity. The sample size of validation studies included in a recent meta-analysis of the PHQ-9 [30] usually ranged from 150 to 600 . The proposed sample therefore falls within the range of validation studies considered methodologically strong.

\section{Household sampling}

Participants were recruited from two districts in South Africa: the City of Cape Town metro district and Ethekwini district in KwaZulu Natal, which encompasses both rural and urban areas. The 'small area level' (SAL) was used as the primary sampling unit from which to select households in the two districts. The SAL is the lowest level of geographic unit for which Census data is publically available, and is a manageable size in terms of population and land area. Population sizes vary across SALs, but usually range between 400 and 1000 individuals.

Only SALs classified as residential were included in the sampling base. SALs were selected for inclusion using systematic sampling, based on data from StatsSA. SALs were stratified by the most common home language, main population group (White, Black, Coloured, Indian), type of area (rural/urban) and most common income bracket. In South Africa, the term 'coloured' is not considered critical, and is used to describe an ethnic group composed primarily of persons of mixed race.

A total of six participants were recruited per SAL, with a maximum of two participants per household. The first household in each SAL was selected using a random starting point (created using a sampling algorithm on the Geographic Information System). Every third household was then selected from this starting point. Nondwelling structures, such as shops, churches and museums, were skipped. Households were still included in the three count method when members were not at home or refused to participate.

This process was repeated until six participants per SAL were reached. If this could not be reached in a particular SAL, then the nearest predetermined oversampled SAL with the same settlement pattern was attempted, in order to reach the full complement of six participants. A total of 75 SALs were selected per sample, including an additional $50 \%$ of oversampled SALs.

\section{Participants}

To be eligible, participants had to be aged 15 years or more, and be able to provide consent. Their home language had to be Xhosa, Afrikaans or Zulu, depending on the district, and be considered household members. This was defined as relatives or non-relatives who lived under the same roof or within the same compound, shared resources, and slept in the house for at least four nights a week. Live-in domestic workers and lodgers were regarded as separate households.

\section{Training}

All fieldworkers conducting the interviews received one week of training by a registered counsellor (TD), on mental illness, administration of the tools, and methodological procedures. The first part of the training consisted of general psychoeducation on symptoms of depression and available treatments, and open discussions on the fieldworkers' knowledge or experience of depression. The second part of the training included a back-translation of the translated MINI, as a cognitive testing exercise, to ensure the fieldworkers had a full understanding of the concepts of symptoms assessed in the MINI, and to ensure these corroborated with the translators' translation. Fieldworkers were then trained to administer the MINI and the other screening tools, facilitated by role plays during which inter-rater reliability was also informally assessed. The depth of training on depression, in addition to the tool itself, was essential to ensure the accuracy of the fieldworkers' diagnostic assessments, and ensure that the data collected were robust and the interpretation of results reliable. Finally, TD spent three days with each fieldwork team at the start of data collection, shadowing all interviews conducted to 
monitor the quality of the MINI assessment and of the accuracy of diagnoses made.

\section{Procedure}

Xhosa and Afrikaans speaking participants were recruited from the City of Cape Town metro district and Zulu speaking participants from the Ethekwini district. Each sample of 300 participants was recruited by one team, comprising of two experienced, trained fieldworkers. Aerial maps of the SALs were printed and provided to the fieldworkers to navigate the SALs. The starting point for the SAL and non-dwelling structures were indicated on the maps. Fieldworkers first approached the households to determine that the language criterion was met. If a household member was present, eligible and agreed, he or she was asked to provide a list of all eligible members in the household, even if they were not present at the time of the visit. Two participants were then randomly selected, using the Dice method: a number was assigned to each eligible household member and an 18-faced dice was thrown to select the assigned number for individuals to be recruited. Appointments were made if selected individuals in the household were not present. A missed appointment was considered as a refusal.

Data were collected electronically, with the use of mobile devices. The interview was administered by the same fieldworkers involved in the recruitment process. The CES-D-10, PHQ9 and WHODAS 2.0 were administered separately from the socio-economic section and MINI 6.0 depression module, and by a different fieldworker, to avoid response bias. Each section of the interview was conducted in a private area of the participant's home, away from other household members and the second fieldworker. Minors completed the interview in the presence of the consenting caregiver. The full interview lasted approximately $45 \mathrm{~min}$.

\section{Statistical analysis}

The data collected were transferred to Stata version 13, where analyses were conducted separately for each sample. Descriptive statistics were used to describe the socio-demographic characteristics of the participants, their screening scores and depression diagnosis. A review of kurtosis and skewness suggested that none of the scores on the CES-D-10, PHQ-9 or WHODAS 2.0 were normally distributed, so non-parametric tests and medians (interquartile range; IQR) were reported throughout the analysis. Probability weights were calculated to estimate the population-level prevalence of depression, taking into account the selection of eligible SALs among the districts, and the probability of a household being selected within an SAL and of an individual being selected within a household. Nonparametric independent tests were used to compare CES-D-10 scores between depressed and non-depressed participants. The internal reliability of the CES-D-10 and PHQ-9 were assessed using Cronbach's Alpha. The CES-D-10's convergent validity was determined by assessing its correlation with the WHODAS 2.0 and the PHQ-9. An exploratory factor analysis with varimax rotation was applied to investigate the construct validity of the CES-D-10, using the Kaiser Test and scree plot to identify latent dimensions of the scale. Finally, Receiver Operating Characteristics (ROC) curves were used to examine the CES-D-10 and PHQ-9's criterion validity against the MINI 6.0. Optimal cut-off scores were identified as the best balance between sensitivity and specificity values, giving equal weight to both measures. The area under the ROC curve for the CES-D-10 was compared to that of the PHQ-9 using the DeLong method [35].

\section{Ethical considerations}

This study was approved by the University of Cape Town's Health Sciences Faculty Human Research Ethics committee (REF: 209/2016). Consent and assent forms were translated in all three languages and completed by all participants who agreed to participate. A R20 supermarket voucher was given to each participant, at the end of the interview. Participants who were diagnosed with depression were given a brochure on depression, and a list of local non-governmental organisations and toll-free numbers they could contact for counselling. Participants who reported suicidal behaviour were referred to the mental health nurse at a primary health care clinic of their choice. Suicide behaviours were considered present if participants answered 'yes' to the MINI 6.0 item ("Did you repeatedly consider hurting yourself, feel suicidal or wish that you were dead? Did you attempt suicide or plan a suicide?"), or answered 'several days' or more to PHQ9 item ("Thoughts that that you would be better off dead or of hurting yourself in some way").

\section{Results}

A total of 944 participants were recruited: 307 in the Zulu sample, 334 in the Afrikaans sample and 303 in the Xhosa sample. One participant in the Zulu sample and two in the Afrikaans sample did not complete the questionnaire (Fig. 1). The original intention was to recruit two types of population group in the Afrikaans sample: one third 'white' and two-thirds 'coloured', to be representative of the Afrikaans population in the district. However, the rate of refusals was high among the white population, and only 39 white participants were recruited. Given that the socio-economic characteristics of the white and coloured populations differed significantly 


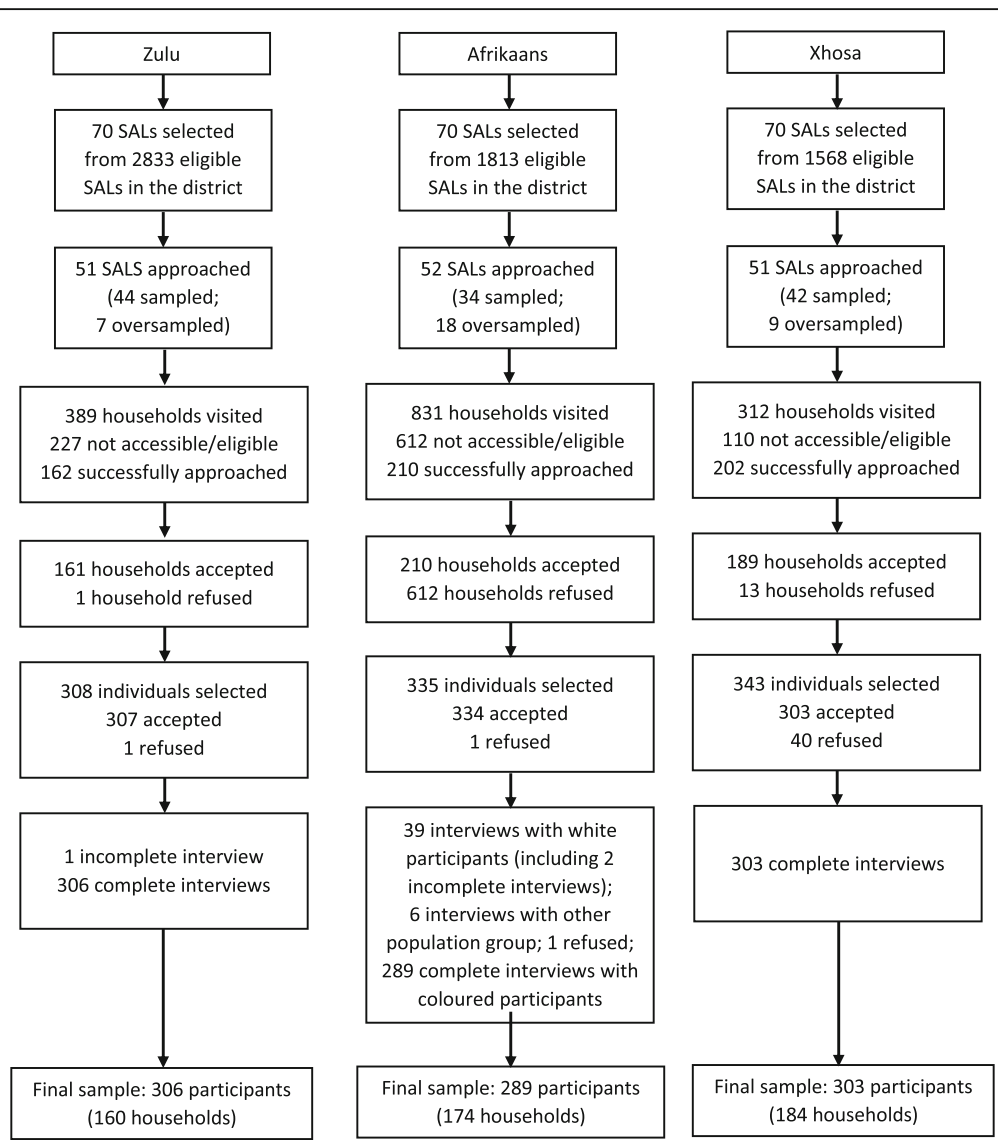

Fig. 1 Recruitment process for the Zulu, Afrikaans and Xhosa samples

in the study, the 39 white participants and 6 participants reporting to be other than coloured, were excluded from the analysis. To increase the Afrikaans coloured sample, additional participants were recruited from the remaining oversampled Afrikaans SALs. The final sample included in the analysis was therefore 306 for the Zulu sample, 289 in the coloured Afrikaans sample and 303 in the Xhosa sample.

\section{Sample demographic and socio-economic characteristics}

The majority of participants across samples were recruited from urban (formal and informal) settlements (Table 1). Half of the Zulu sample (53.8\%), and a third of the Afrikaans sample lived in formal houses. The majority of participants in the Afrikaans sample, however, lived in government housing. A third of the Xhosa sample also reported living in government houses, and nearly half in informal dwellings. The majority of households across samples reported having access to electricity, piped water and private flush toilet facilities inside or outside the dwelling.

The majority of participants sampled were women (67.7-70.6\% across samples). Participants in the Afrikaans sample were older $($ Mean $=44.7, \mathrm{SD}=17.72$, range: $15-84)$ compared to participants in the Zulu sample (Mean $=33$, $\mathrm{SD}=15.63$, range: $15-86)$ and Xhosa sample (Mean $=34.0$, $\mathrm{SD}=13.49$, range: $15-77)$. A larger proportion of adolescents were recruited in the Xhosa sample $(N=27 ; 8.9 \%)$ compared to the Zulu and Afrikaans samples (2.3 and 2.4\%, respectively). Most of the participants reported being single in the Zulu (76.4\%) and Xhosa (57.4\%) samples, while this group was a minority in the Afrikaans sample (36.7\%). Nearly a third of the Zulu sample reported having reached the end of high school, which was the case only for $13.6 \%$ of the participants in the Afrikaans sample and $22.4 \%$ in the Xhosa sample. A minority reported having tertiary education across samples (4.7-11.1\%). A fifth of the Zulu sample and over a third of the Xhosa sample reported being employed. Another 40\% in the Zulu sample and 34\% in the Xhosa reported being unemployed and looking for work. The remaining participants were mainly school or university students. On the other hand, participants in the Afrikaans sample consisted mostly of 'stay at home' individuals (looking after children or home; 24.9\%), unemployed (23.6\%) and retired (21.8\%) individuals. A third of each sample reported not receiving a personal income. Remaining participants usually indicated earning less than R5,000 (US\$ 320) per month. 
Table 1 Socio-demographic and socio-economic characteristics of the three samples

\begin{tabular}{|c|c|c|c|c|c|c|}
\hline & Zulu & & Afrikaa & & Xhosa & \\
\hline & $N$ & $\%$ & $N$ & $\%$ & $N$ & $\%$ \\
\hline Age & 306 & & 288 & & 303 & \\
\hline Median & 33 & & 47 & & 32 & \\
\hline $25^{\text {th }}-75^{\text {th }}$ percentile & $23-47$ & & $28-59$ & & $23-44$ & \\
\hline Gender & 306 & & 289 & & 303 & \\
\hline Male & 95 & 31.1 & 85 & 29.4 & 98 & 32.3 \\
\hline Female & 211 & 68.9 & 204 & 70.6 & 205 & 67.7 \\
\hline Population group & 306 & & 289 & & 303 & \\
\hline African & 306 & 100 & 0 & - & 303 & 100.0 \\
\hline Coloured & 0 & - & 289 & 100.0 & & \\
\hline Marital status & 305 & & 288 & & 303 & \\
\hline Single & 233 & 76.4 & 106 & 36.8 & 174 & 57.4 \\
\hline Living with partner but not married & 16 & 5.3 & 2 & 0.7 & 46 & 15.2 \\
\hline Married and living together & 21 & 6.9 & 123 & 42.7 & 56 & 18.5 \\
\hline Married but not living together & 7 & 2.3 & 8 & 2.8 & 14 & 4.6 \\
\hline Divorced or widowed & 28 & 9.1 & 49 & 17.0 & 13 & 4.3 \\
\hline Educational level & 305 & & 286 & & 303 & \\
\hline No schooling/Grade $0-2$ & 8 & 2.6 & 6 & 2.1 & 6 & 2.0 \\
\hline Primary school & 51 & 16.8 & 67 & 23.4 & 31 & 10.2 \\
\hline Some secondary school & 117 & 38.5 & 156 & 54.6 & 184 & 60.7 \\
\hline End of secondary school & 94 & 30.9 & 39 & 13.6 & 68 & 22.4 \\
\hline Post-secondary school & 33 & 10.9 & 17 & 5.9 & 9 & 3.0 \\
\hline Primary school & 1 & 0.3 & 1 & 0.3 & 5 & 1.7 \\
\hline Employment & 305 & & 289 & & 303 & \\
\hline Working for pay & 62 & 20.3 & 50 & 17.3 & 105 & 34.7 \\
\hline Self-employed & 4 & 1.3 & 6 & 2.1 & 9 & 3.0 \\
\hline Scholar/student & 48 & 15.7 & 19 & 6.6 & 59 & 19.5 \\
\hline Homemaker & 1 & 0.3 & 72 & 24.9 & 4 & 1.3 \\
\hline Long term sick or disabled & 1 & 0.3 & 11 & 3.8 & 4 & 1.3 \\
\hline Retired & 38 & 12.5 & 63 & 21.8 & 11 & 3.6 \\
\hline Unemployed and looking for a job & 119 & 39.0 & 64 & 22.2 & 104 & 34.3 \\
\hline Unemployed but not looking for a job & 32 & 10.5 & 4 & 1.4 & 7 & 2.3 \\
\hline Personal monthly income & 306 & & 289 & & 303 & \\
\hline RO & 107 & 35.0 & 105 & 36.3 & 98 & 32.4 \\
\hline R1-R500 & 51 & 16.7 & 15 & 5.2 & 47 & 15.5 \\
\hline $\mathrm{R} 501-\mathrm{R} 1,000$ & 30 & 9.8 & 23 & 8.0 & 27 & 8.9 \\
\hline R1001-R2000 & 61 & 19.9 & 98 & 33.9 & 57 & 18.8 \\
\hline R2000-R5000 & 18 & 5.9 & 20 & 6.9 & 64 & 21.1 \\
\hline R5001-R10000 & 6 & 2.0 & 12 & 4.2 & 7 & 2.3 \\
\hline R10001-R20000 & 6 & 2.0 & 5 & 1.7 & 2 & 0.7 \\
\hline More than R20,000 & 0 & - & 5 & 1.7 & 0 & - \\
\hline Don't know/Refused & 27 & 8.8 & 6 & 2.1 & 1 & 0.3 \\
\hline Personally own: & 306 & & 289 & & 303 & \\
\hline
\end{tabular}


Table 1 Socio-demographic and socio-economic characteristics of the three samples (Continued)

\begin{tabular}{|c|c|c|c|c|c|c|}
\hline A motor vehicle & 13 & 4.3 & 31 & 10.7 & 12 & 4.0 \\
\hline A motorcycle & 0 & 0 & 3 & 1.0 & 0 & - \\
\hline A computer/laptop & 18 & 5.9 & 24 & 8.3 & 16 & 5.3 \\
\hline A cell phone & 288 & 94.1 & 206 & 71.3 & 269 & 88.8 \\
\hline Settlement type & 160 & & 172 & & 184 & \\
\hline Urban-formal & 84 & 52.5 & 166 & 96.5 & 123 & 66.9 \\
\hline Urban-informal & 49 & 30.6 & 6 & 3.5 & 61 & 33.1 \\
\hline Rural-traditional & 27 & 16.9 & 0 & - & 0 & - \\
\hline Dwelling type & 160 & & 174 & & 184 & \\
\hline Informal/backyard dwelling & 24 & 15.0 & 4 & 2.3 & 81 & 44.0 \\
\hline RDP (government) house ${ }^{a}$ & 45 & 28.1 & 105 & 60.3 & 69 & 37.5 \\
\hline Flat & 3 & 1.9 & 7 & 4.0 & 5 & 2.7 \\
\hline Formal house & 86 & 53.8 & 58 & 33.3 & 25 & 13.6 \\
\hline Other & 2 & 1.2 & 0 & - & 4 & 2.2 \\
\hline Electricity & 160 & & 174 & & 184 & \\
\hline Yes & 152 & 95.0 & 172 & 98.9 & 180 & 97.3 \\
\hline Source of drinking-water & 158 & & 174 & & 184 & \\
\hline Piped water on site or in yard & 129 & 81.7 & 170 & 97.7 & 118 & 64.1 \\
\hline Public tap & 18 & 11.4 & 4 & 2.3 & 64 & 34.8 \\
\hline Borehole off site/communal & 5 & 3.2 & 0 & - & 0 & - \\
\hline From neighbours & 2 & 1.3 & 0 & - & 2 & 1.1 \\
\hline Other & 4 & 2.5 & 0 & - & 0 & - \\
\hline Type of toilet & 160 & & 174 & & 183 & \\
\hline Flush toilet inside dwelling (private) & 91 & 56.9 & 164 & 94.3 & 78 & 42.6 \\
\hline Flush toilet outside dwelling (private) & 3 & 1.9 & 7 & 4.0 & 56 & 30.6 \\
\hline Private bucket system or pit latrine & 43 & 26.9 & 0 & - & 4 & 2.2 \\
\hline Communal flush toilet & 5 & 3.1 & 2 & 1.1 & 21 & 11.5 \\
\hline Communal bucket or pit latrine & 16 & 10.0 & 1 & 0.6 & 22 & 12.0 \\
\hline Other & 2 & 1.2 & 0 & - & 2 & 1.1 \\
\hline Number of members aged $15+$ years & 160 & & 174 & & 184 & \\
\hline Median & 4 & & 4 & & 2 & \\
\hline $25^{\text {th }}-75^{\text {th }}$ percentiles & $2.5-5$ & & $2-5$ & & $2-4$ & \\
\hline
\end{tabular}

${ }^{2}$ The Reconstruction and Development Programme is a South African policy framework put in place by the African National Congress (ANC) government in 1994. Part of the RDP plan was to build 1,000,000 low-cost houses to overcome inadequate housing in urban townships and rural settlements

\section{Prevalence of major depression}

The prevalence of depression in the three samples and across demographic groups are reported in Table 2. A similar proportion of participants in the Zulu and Xhosa samples were diagnosed with depression (6.9\%), but a much higher prevalence was found in the Afrikaans sample (18.0\%). Only one adolescent, in the Afrikaans sample, was diagnosed with depression.

None of the socio-demographic measures were associated with a diagnosis of depression in the Xhosa sample. In the Zulu sample, gender, age, marital status and employment status were associated with depression. A significantly higher proportion of participants with depression were women (90\%), were aged 60 years or more $(28 \%)$, were retired $(39 \%)$, and were either divorced or widowed, compared to nondepressed participants $(67,8,11$ and $8 \%$, respectively). A greater proportion of non-depressed participants reported being employed (21\%) or studying (16\%) compared to non-depressed participants (14 and $9 \%$ respectively).

In the Afrikaans sample, age and marital status were associated with depression, as well as dwelling type: a greater proportion of depressed participants were 
Table 2 MINI diagnosis of depression across demographic groups

\begin{tabular}{|c|c|c|c|c|c|c|c|c|c|}
\hline & \multicolumn{3}{|l|}{ Zulu sample } & \multicolumn{3}{|c|}{ Afrikaans sample } & \multicolumn{3}{|l|}{ Xhosa sample } \\
\hline & \multicolumn{2}{|c|}{ MINI diagnosis $(n=306)$} & \multirow[t]{2}{*}{$x^{2}$} & \multicolumn{2}{|c|}{ MINI diagnosis $(n=289)$} & \multirow[t]{2}{*}{$x^{2}$} & \multicolumn{2}{|c|}{ MINI diagnosis $(n=303)$} & \multirow[t]{2}{*}{$x^{2}$} \\
\hline & No $(n=285)$ & Yes $(n=21)$ & & No $(n=237)$ & Yes $(n=52)$ & & No $(n=282)$ & Yes $(n=21)$ & \\
\hline \multicolumn{10}{|l|}{ Gender } \\
\hline Male & $93(33 \%)$ & $2(10 \%)$ & $4.9^{\mathrm{a}}$ & $72(30 \%)$ & $13(25 \%)$ & 0.6 & $94(33 \%)$ & $4(19 \%)$ & 1.8 \\
\hline Female & $192(67 \%)$ & $19(90 \%)$ & & $165(70 \%)$ & $39(75 \%)$ & & $188(67 \%)$ & $17(81 \%)$ & \\
\hline \multicolumn{10}{|l|}{ Age } \\
\hline $15-20$ & $28(10 \%)$ & $1(5 \%)$ & $9.9^{\mathrm{a}}$ & $25(11 \%)$ & $4(8 \%)$ & $12.0^{\mathrm{a}}$ & $54(19 \%)$ & $1(5 \%)$ & 6.7 \\
\hline $21-40$ & $161(56 \%)$ & $9(43 \%)$ & & 76 (32\%) & $18(35 \%)$ & & $147(52 \%)$ & $10(48 \%)$ & \\
\hline $41-60$ & $73(26 \%)$ & $5(24 \%)$ & & 77 (33\%) & $27(52 \%)$ & & 71 (25\%) & $10(48 \%)$ & \\
\hline 61 or older & $23(8 \%)$ & $6(28 \%)$ & & $58(25 \%)$ & $3(6 \%)$ & & $10(4 \%)$ & 0 & \\
\hline \multicolumn{10}{|l|}{ Marital status } \\
\hline Single & 219 (77\%) & 14 (67\%) & $11.4^{\mathrm{a}}$ & 87 (37\%) & $19(37 \%)$ & $13.0^{\mathrm{a}}$ & 160 (57\%) & 14 (67\%) & 1.0 \\
\hline Living with partner & $16(6 \%)$ & 0 & & 0 & $2(4 \%)$ & & $44(16 \%)$ & $2(9 \%)$ & \\
\hline Married (living together) & $20(7 \%)$ & $1(5 \%)$ & & $106(45 \%)$ & 17 (33\%) & & $53(19 \%)$ & $3(14 \%)$ & \\
\hline Married (not living together) & $7(2 \%)$ & 0 & & $5(2 \%)$ & $3(6 \%)$ & & $13(5 \%)$ & $1(5 \%)$ & \\
\hline Divorced or widowed & $22(8 \%)$ & $6(29 \%)$ & & $39(16 \%)$ & $10(20 \%)$ & & $12(4 \%)$ & $1(5 \%)$ & \\
\hline \multicolumn{10}{|l|}{ Education level } \\
\hline No schooling & $8(3 \%)$ & 0 & 7.5 & $4(2 \%)$ & $2(4 \%)$ & 3.7 & $6(2 \%)$ & 0 & 2.6 \\
\hline Primary school & $44(15 \%)$ & $7(33 \%)$ & & 57 (24\%) & $10(19 \%)$ & & $28(10 \%)$ & $3(14 \%)$ & \\
\hline Some secondary school & $108(38 \%)$ & $9(43 \%)$ & & $123(53 \%)$ & $33(63 \%)$ & & $174(62 \%)$ & $10(48 \%)$ & \\
\hline End of secondary school & $91(32 \%)$ & $3(14 \%)$ & & $34(15 \%)$ & $5(10 \%)$ & & $61(22 \%)$ & $7(33 \%)$ & \\
\hline Post-secondary school & $1(0 \%)$ & $1(5 \%)$ & & $16(7 \%)$ & $2(4 \%)$ & & $13(5 \%)$ & $1(5 \%)$ & \\
\hline \multicolumn{10}{|l|}{ Employment status } \\
\hline Working for pay & $59(21 \%)$ & $3(14 \%)$ & $18.1^{\mathrm{a}}$ & 45 (19\%) & $5(10 \%)$ & 9.8 & $100(35 \%)$ & $5(24 \%)$ & 5.2 \\
\hline Self-employed & $2(1 \%)$ & $2(9 \%)$ & & $5(2 \%)$ & $1(2 \%)$ & & $9(3 \%)$ & 0 & \\
\hline Scholar/student & $46(16 \%)$ & $2(9 \%)$ & & $16(7 \%)$ & $3(6 \%)$ & & $56(20 \%)$ & $3(14 \%)$ & \\
\hline Homemaker & $1(0 \%)$ & 0 & & $54(23 \%)$ & $18(35 \%)$ & & $4(1 \%)$ & 0 & \\
\hline Long term sick/disabled & $1(0 \%)$ & 0 & & $8(3 \%)$ & $3(6 \%)$ & & $4(1 \%)$ & 0 & \\
\hline Retired & $32(11 \%)$ & $6(29 \%)$ & & $57(24 \%)$ & $6(12 \%)$ & & $10(3 \%)$ & $1(5 \%)$ & \\
\hline Unemployed (looking) & $113(40 \%)$ & $6(29 \%)$ & & $49(21 \%)$ & $15(29 \%)$ & & 93 (33\%) & $11(52 \%)$ & \\
\hline Unemployed (not looking) & $30(11 \%)$ & $2(9 \%)$ & & $3(1 \%)$ & $1(2 \%)$ & & $6(2 \%)$ & $1(5 \%)$ & \\
\hline \multicolumn{10}{|l|}{ Personal income } \\
\hline RO & $103(36 \%)$ & $4(19 \%)$ & 4.6 & 85 (37\%) & $20(39 \%)$ & 5.1 & 93 (33\%) & $5(24 \%)$ & 9.9 \\
\hline R1-R500 & $48(17 \%)$ & $3(14 \%)$ & & $10(4 \%)$ & $5(10 \%)$ & & 40 (14\%) & $7(33 \%)$ & \\
\hline R501-R1,000 & $27(9 \%)$ & $3(14 \%)$ & & $17(7 \%)$ & $6(12 \%)$ & & 27 (10\%) & 0 & \\
\hline R1001-R2000 & $54(19 \%)$ & $7(33 \%)$ & & $93(36 \%)$ & $15(19 \%)$ & & $51(18 \%)$ & $6(29 \%)$ & \\
\hline R2000-R5000 & $16(6 \%)$ & $2(9 \%)$ & & $18(8 \%)$ & $2(4 \%)$ & & $62(22 \%)$ & $2(10 \%)$ & \\
\hline More than R5000 & $11(4 \%)$ & $1(5 \%)$ & & $19(8 \%)$ & $3(6 \%)$ & & $8(3 \%)$ & $1(5 \%)$ & \\
\hline Dwelling type & $(n=142)$ & $(n=16)$ & & $(n=136)$ & $(n=38)$ & & $(n=169)$ & $(n=11)$ & 0.5 \\
\hline Informal/backyard dwelling & $21(15 \%)$ & $3(19 \%)$ & 5.1 & $1(1 \%)$ & $3(8 \%)$ & $9.0^{\mathrm{a}}$ & $76(45 \%)$ & $5(45 \%)$ & \\
\hline RDP house & $37(26 \%)$ & $8(50 \%)$ & & $84(62 \%)$ & $21(55 \%)$ & & $65(38 \%)$ & $4(36 \%)$ & \\
\hline Flat & $3(2 \%)$ & 0 & & $4(3 \%)$ & $3(8 \%)$ & & $5(3 \%)$ & 0 & \\
\hline Formal house & $81(56 \%)$ & $5(31 \%)$ & & 47 (35\%) & $11(29 \%)$ & & $23(14 \%)$ & $2(18 \%)$ & \\
\hline
\end{tabular}

${ }^{a}$ significant at $<0.05$ level 
between 40 and 60 years old (52\%), and living in informal settlements. More non-depressed participants reported being married and living together (45\%) in comparison to depressed participants (33\%).

Taking into account the sampling strategy, the weighted population prevalence of depression was 5.9\% (95\% CI 3.0-11.4) in the Zulu sample, $18.9 \%$ (95\% CI 13.5\%-25.7\%) in the Afrikaans sample, and 6.9\% (95\% CI $4.0 \%-11.5 \%)$ in the Xhosa sample.

\section{Depression screening and functioning scales}

Scores on the CES-D-10 were significantly higher for participants diagnosed with depression (Zulu: median = 15 , IQR $=8$; Afrikaans: median $=20, \mathrm{IQR}=11$; Xhosa: median $=18 ; \mathrm{IQR}=6)$ compared to those who were not depressed (Zulu: median $=9, \mathrm{IQR}=6$; Afrikaans: median = 3; $\mathrm{IQR}=8$; Xhosa: median $=4 ; \mathrm{IQR}=5$ ). Adolescents did not have significantly different CES-D-10 scores compared to adults in the Zulu or Afrikaans samples, but had significantly lower CES-D-10 scores in the Xhosa sample (median $=3$; IQR $=4)$ compared to adults (median $=4$; $\mathrm{IQR}=6)(U=186937.0, p<.05)$.

The three scales had adequate inter-item reliability across samples (CES-D-10: 0.69-0.89; PHQ-9: 0.730.86; WHODAS 2.0: 0.74-0.84). CES-D-10 item-rest correlations were all above $0.37,0.40$ and 0.60 in the Zulu, Afrikaans and Xhosa samples, respectively, with the exception of items 5 ("I felt hopeful about the future") and 8 ("I was happy"), which consistently had the lowest item-rest correlations, ranging from 0.03 to 0.30 and 0.04 to 0.52 , respectively. Internal reliability and item-rest correlations for item 5 and 8 were higher in the Afrikaans sample.

\section{Concurrent validity of the CES-D-10}

The correlation between the CES-D-10 and the other screening tools were all above .5 and statistically significant at the 0.001 level, besides the correlation between the CES-D-10 and the WHODAS 2.0, which was lower in the Xhosa sample $(\mathrm{Rho}=0.37)$.

\section{Construct validity of the CES-D-10}

The exploratory factor analysis suggests a two-factor solution in the Zulu and Xhosa samples, explaining 42.7 and $46.7 \%$ of the variance on the CES-D-10, respectively. A one-factor model in the Afrikaans sample was identified, explaining $51.6 \%$ of the variance. Item-factor correlations are shown in Table 3. All items pertaining to negative affect and somatic symptoms loaded highly on Factor $1(0.55-0.71)$, and items 5 and 8 , which refer to positive affect, either loaded highly on Factor 2 in the Zulu and Xhosa samples, or less well on Factor 1 in the Afrikaans sample.

\section{Criterion validity of the CES-D-10 and PHQ-9}

The CES-D-10 and PHQ-9 ROC curves are presented in Fig. 2. The area under the ROC curve (AUROC) for both screening tools were good to excellent across all three samples (0.81-0.94). In the Zulu sample, the AUROC for the CES-D-10 $(0.81 ; 95 \%$ CI $0.71-0.90 ;<0.05)$ was slightly lower than that of the PHQ-9 $(0.85 ; 95 \% \mathrm{CI}$ $0.78-0.92$; $<0.05)$, but not significantly different. In the Afrikaans sample, the AUROC for the CES-D-10 was significantly higher $(0.93 ; 95 \%$ CI $0.90-0.96 ;<0.05)$ than that of the PHQ-9 $(0.88$; $95 \%$ CI $0.84-0.93 ;<0.05)\left(X^{2}=0.43\right.$, $p<0.05)$. The AUROC for the CES-D-10 (0.94; 95\% CI $0.89-0.99$; $<0.05)$ was also higher in the Xhosa sample, compared to the PHQ-9 $(0.90 ; 95 \%$ CI $0.83-0.98$; <0.05), but this difference was not statistically significantly.

\section{CES-D-10}

The sensitivity and specificity of each cut-off point on the CES-D-10 and PHQ-9 are presented in Table 4. In the Zulu sample, a cut-off of 12 on the CES-D-10 presented the most balanced sensitivity $(71.4 \%)$ and specificity $(72.6 \%)$, correctly classifying $72.6 \%$ of participants.

Table 3 Varimax-rotated factor loadings (>0.3) and unique variances of CES-D-10 items

\begin{tabular}{|c|c|c|c|c|c|}
\hline \multirow[t]{2}{*}{ CES-D-10 items } & \multicolumn{2}{|l|}{ Zulu } & \multirow{2}{*}{$\begin{array}{l}\text { Afrikaans } \\
\text { Factor } 1\end{array}$} & \multicolumn{2}{|l|}{ Xhosa } \\
\hline & Factor 1 & Factor 2 & & Factor 1 & Factor 2 \\
\hline 1. I was bothered by things that usually don't bother me & 0.57 & & 0.78 & 0.55 & \\
\hline 2. I had trouble keeping my mind on what I was doing & 0.57 & & 0.83 & 0.66 & \\
\hline 3. I felt depressed & 0.64 & & 0.83 & 0.76 & \\
\hline 4. I felt that everything I did was an effort & 0.68 & & 0.71 & 0.61 & \\
\hline 5. I felt hopeful about the future & & 0.69 & 0.36 & & 0.80 \\
\hline 6. I felt fearful & 0.56 & & 0.67 & 0.53 & \\
\hline 7. My sleep was restless & 0.55 & & 0.70 & 0.64 & 0.30 \\
\hline 8. I was happy & & 0.77 & 0.60 & & 0.67 \\
\hline 9. I felt lonely & 0.71 & & 0.80 & 0.69 & \\
\hline 10. I could not "get going" & 0.66 & & 0.77 & 0.61 & \\
\hline
\end{tabular}




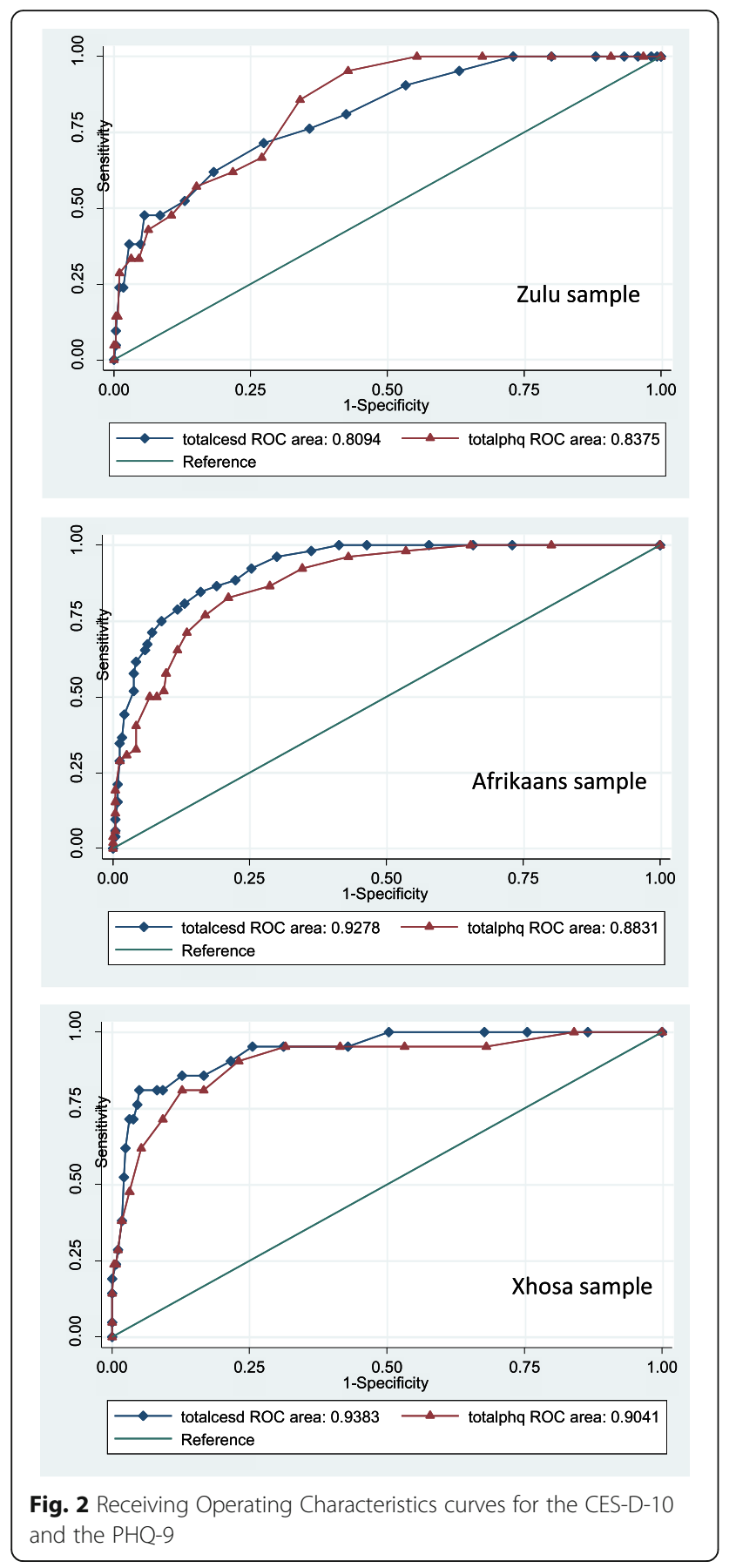

However, the positive predictive value (PPV) was very low, suggesting that only $16.1 \%$ of those who scored 12 or above on the CES-D-10 were depressed. This is due to the low prevalence depression in this sample (6.6\%). In the Xhosa sample, where the prevalence of depression was also low, a cut-off of 10 on the CES-D-10 presented the most balanced sensitivity (85.7\%) and specificity (87.2\%), correctly classifying $84.1 \%$ of participants. Again, the PPV was very low (33.3\%). However, a higher cut-off of 13 still had adequate sensitivity (81.0\%) and specificity (95.0\%), though less balanced, and an acceptable PPV (54.8\%), altogether correctly classifying $94.1 \%$ of the sample. Finally, in the Afrikaans sample, a cut-off of 11 on the CES-D-10 presented the most balanced sensitivity (84.6\%) and specificity (84.0\%), correctly classifying $84.1 \%$ of participants. The PPV was higher in this sample, with $53.7 \%$ of participants with a CES-D-10 score of 11 or above having a diagnosis of depression.

\section{PHQ-9}

Sensitivity and specificity values on the PHQ-9 were generally lower than on the CES-D-10 in all three samples. In the Zulu and Xhosa sample, a cut-off of 8 on the PHQ-9 provided the best balance of sensitivity and specificity (Zulu: 66.7 and 73.1\%; Xhosa: 81.0 and 87.2\%). While 72.6 and $86.8 \%$ of participants were correctly classified in the Zulu and Xhosa samples, respectively, the PPV was also low (15.4 and 32.1\%, respectively). Selecting another cut-off score on the PHQ-9 did not improve the PPV without being detrimental to sensitivity or specificity values. On the other hand, a cut-off of 7 on the PHQ-9 in the Afrikaans sample provided the best balance of sensitivity (82.7\%) and specificity (79.1\%), correctly classifying $79.7 \%$ of participants; $46.7 \%$ of participants screening positive using this cut-off were actually depressed.

\section{Discussion}

The present study sought to investigate the reliability and validity of the CES-D-10 among three language groups in South Africa.

The sampling strategy allowed us to recruit a representative sample of the Xhosa, Zulu and coloured Afrikaans population in the Cape Town Metro and Ethekwini districts, so a population weighted prevalence of depression could be calculated. The estimated population prevalence of $5.9 \%$ in the Zulu and $6.9 \%$ in the Xhosa populations are similar to the national 12-month prevalence for major depression (4.9\%) reported in the SASH study [36]. The estimated population prevalence of $18 \%$ in the coloured Afrikaans population was relatively high. Interestingly, the odds of suffering from a mood disorder in Williams et al [36]'s study were also higher in the Coloured community, compared to the White or African communities, but this finding was not statistically significant. Unfortunately, too few adolescents were recruited, and almost none reported having depression, so it was not possible to estimate the population prevalence of depression among adolescents. For ethical reasons, the adolescents' caregivers were present during the interview. It is therefore possible that the very low prevalence among adolescents in this study may also have been due to a lack of confidentiality when providing their responses. 
Table 4 Optimal cut-off scores on the CES-D-10 and PHQ-9 for the detection of major depressive disorder

\begin{tabular}{|c|c|c|c|c|c|c|c|c|c|c|c|c|c|c|c|}
\hline \multirow{2}{*}{$\begin{array}{l}\text { Cut-off } \\
\text { score }\end{array}$} & \multicolumn{5}{|l|}{ Zulu } & \multicolumn{5}{|l|}{ Afrikaans } & \multicolumn{5}{|l|}{ Xhosa } \\
\hline & Sensitivity & Specificity & PPV & NPV & $\begin{array}{l}\text { Correctly } \\
\text { classified }\end{array}$ & Sensitivity & Specificity & PPV & NPV & $\begin{array}{l}\text { Correctly } \\
\text { classified }\end{array}$ & Sensitivity & Specificity & PPV & NPV & $\begin{array}{l}\text { Correctly } \\
\text { classified }\end{array}$ \\
\hline \multicolumn{16}{|c|}{ CES-D-10 } \\
\hline$\geq 5$ & 100.0 & 11.9 & 7.7 & 100.0 & 18.0 & 100.0 & 58.7 & 34.7 & 100.0 & 66.1 & 95.2 & 57.1 & 14.2 & 99.4 & 59.7 \\
\hline$\geq 6$ & 100.0 & 20.0 & 8.4 & 100.0 & 25.5 & 98.1 & 63.7 & 37.2 & 99.3 & 69.9 & 95.2 & 68.8 & 18.5 & 99.5 & 70.6 \\
\hline$\geq 7$ & 100.0 & 27.0 & 9.2 & 100.0 & 32.0 & 96.2 & 70.0 & 41.3 & 98.8 & 74.7 & 95.2 & 74.5 & 21.7 & 99.5 & 75.9 \\
\hline$\geq 8$ & 95.2 & 36.8 & 10.0 & 99.1 & 40.9 & 92.3 & 74.7 & 44.4 & 97.8 & 77.9 & 90.5 & 78.4 & 23.8 & 99.1 & 79.2 \\
\hline$\geq 9$ & 90.5 & 46.7 & 11.1 & 98.5 & 49.7 & 88.5 & 77.7 & 46.5 & 96.8 & 79.6 & 85.7 & 83.3 & 27.7 & 98.7 & 83.5 \\
\hline$\geq 10$ & 81.0 & 57.5 & 12.3 & 97.6 & 59.2 & 85.5 & 81.0 & 50.0 & 96.5 & 82.0 & 85.7 & 87.2 & 33.3 & 98.8 & 87.1 \\
\hline$\geq 11$ & 76.2 & 64.2 & 13.6 & 97.3 & 65.0 & 84.6 & 84.0 & 53.7 & 96.1 & 84.1 & 81.0 & 90.8 & 39.5 & 98.5 & 90.1 \\
\hline$\geq 12$ & 71.4 & 72.6 & 16.1 & 97.2 & 72.6 & 80.8 & 86.9 & 57.5 & 95.4 & 85.8 & 81.0 & 91.8 & 42.5 & 98.5 & 91.1 \\
\hline$\geq 13$ & 61.9 & 81.8 & 20.0 & 96.7 & 80.4 & 78.9 & 88.2 & 59.4 & 95.0 & 86.5 & 81.0 & 95.0 & 54.8 & 98.5 & 94.1 \\
\hline$\geq 14$ & 52.4 & 87.0 & 22.9 & 96.1 & 84.6 & 76.5 & 91.1 & 65.0 & 94.3 & 88.2 & 76.2 & 95.4 & 55.2 & 98.2 & 94.1 \\
\hline \multicolumn{16}{|l|}{ PHQ-9 } \\
\hline$\geq 4$ & 100.0 & 32.6 & 9.9 & 100.0 & 37.3 & 96.2 & 57.7 & 33.6 & 98.5 & 64.7 & 95.2 & 58.5 & 14.6 & 99.4 & 61.1 \\
\hline$\geq 5$ & 100.0 & 44.3 & 11.7 & 100.0 & 48.2 & 92.3 & 65.8 & 37.5 & 97.5 & 70.6 & 95.2 & 68.4 & 18.4 & 99.5 & 70.3 \\
\hline$\geq 6$ & 95.2 & 57.1 & 14.1 & 99.4 & 59.7 & 86.5 & 71.4 & 40.2 & 96.0 & 74.1 & 90.5 & 77.0 & 22.6 & 99.1 & 77.9 \\
\hline$\geq 7$ & 85.7 & 66.0 & 15.7 & 98.4 & 67.3 & 82.7 & 79.1 & 46.7 & 95.4 & 79.7 & 81.0 & 83.3 & 26.6 & 98.3 & 83.2 \\
\hline$\geq 8$ & 66.7 & 73.1 & 15.4 & 96.7 & 72.6 & 77.0 & 82.9 & 50.0 & 94.2 & 81.8 & 81.0 & 87.2 & 32.1 & 98.4 & 86.8 \\
\hline$\geq 9$ & 61.9 & 78.0 & 17.3 & 96.5 & 76.9 & 71.2 & 86.3 & 53.6 & 93.1 & 83.6 & 71.4 & 90.8 & 36.6 & 97.7 & 89.4 \\
\hline$\geq 10$ & 57.1 & 84.8 & 21.8 & 96.4 & 82.8 & 65.4 & 88.0 & 54.8 & 92.0 & 83.9 & 61.9 & 94.7 & 46.4 & 97.1 & 92.4 \\
\hline$\geq 11$ & 47.6 & 89.4 & 25.0 & 95.9 & 86.5 & 57.7 & 90.2 & 56.6 & 90.6 & 84.3 & 47.6 & 96.8 & 52.6 & 96.1 & 93.4 \\
\hline$\geq 12$ & 42.9 & 93.6 & 33.3 & 95.7 & 90.1 & 51.9 & 90.6 & 55.1 & 89.5 & 83.6 & 38.1 & 98.2 & 61.5 & 95.5 & 94.1 \\
\hline
\end{tabular}

PPV Positive predictive value, NPV Negative predictive value

Optimal cut-off scores are indicated in bold

Scores on the CES-D-10 differed from those reported in the first wave of NIDS. In the present study, the proportion of participants screening $\geq 10$ and $\geq 15$ was consistently higher in the Zulu and Afrikaans samples. The proportion of participants in the Xhosa sample scoring $\geq 10$ (17.8\%) was lower than the $28 \%$ figure reported by NIDS in the Western Cape; however the proportion scoring $\geq 15$ was very similar (approximately $8 \%$ ). The differences in CES-D10 scores reported here may be due to the relatively small and perhaps less representative sample in this study, in comparison with the NIDS sample.

ROC curves suggested that the CES-D-10 is an adequate screening tool to identify individuals at risk of depression. AUROC values were all above the minimum value of .75 , which is considered clinically significant [37]. In the Zulu sample, a cut-off of 12 on the CES-D10 seem to be the most appropriate to indicate high risk of depression, whereas a cut-off of 11 in the Afrikaans sample and 13 in the Xhosa sample were most suitable. Alternatively, a cut-off of 12 may be appropriate in the South African context, as it provides relatively acceptable sensitivity and specificity across all three language groups.
The present study suggests that a cut-off of 10 to indicate high risk of depression, as suggested by Andresen et al. [10], may not be optimal, especially if the screening tool is to be used in clinical settings, which are already overburdened in South Africa. Indeed, if a cut-off of 10 were used, nearly half of the Zulu sample and one third of the Afrikaans sample would be considered at high risk for depression. Also, misclassification of individuals into high or low risk for depression in the Zulu sample would increase from $27.4 \%$ (at a cut-off of 12 ) to $40.8 \%$, and from $5.9 \%$ (at a cut-off of 13 ) to $12.9 \%$ in the Xhosa sample. The difference in misclassification would be less striking in the Afrikaans sample, but would still increase from $15.9 \%$ (at a cut off of 11) to $18.0 \%$.

The CES-D-10 performed well in relation to the PHQ9 and the WHODAS 2.0, suggesting adequate concurrent validity. The internal consistency of the CES-D-10 was also acceptable in the Afrikaans and Xhosa samples, though slightly lower in the Zulu sample. The internal reliability and exploratory factor analysis both suggest that the two positive affect items do not fit well with the other items in the tool, and constitute a second 
dimension. This supports previous evidence on the internal structure of the CES-D-10 among adolescents [15] and the older population in Asia [12, 13], suggesting that the CES-D-10 consists of a depressed affect dimension (including somatic symptoms) and positive affect dimension. In addition, item 5 (hopefulness) consistently performed poorly in comparison to item 8 in the present study. This was also reported in Bradley et al [15]'s validation study among adolescents, where they cautioned about conceptualising hopefulness as a positive affect concept. The order of the questions may also have explained the difference in the performance of the two items, as participants may have been confused by the first positive statement, after having answered a series of negative statements.

In comparison to the original 20-item version of the CES-D, the CES-D-10 has clear benefits. The present study suggests that the shorter version of the tool is still reliable and valid in assessing clinically significant depressive symptoms among the general Xhosa, Zulu and Afrikaans populations in South Africa. As a shorter instrument, the CES-D-10 is less time consuming to administer and therefore more feasible to use in both research and clinical settings, such as part of larger screening activities integrated in health services to identify and refer at-risk individuals.

Overall, the PHQ-9 also performed well across the three samples. A cut-off of 7 or 8 on the PHQ- 9 in the present study was lower than the cut-off of 9 suggested among chronic care patients in the Northwest Province of south Africa [26] and a cut-off of 10 identified among patients attending a high HIVburdened primary care clinic in Johannesburg [27]. Altogether, the psychometric properties of the CESD-10 and PHQ-9 were similar across all three samples. Though the AUROC was only slightly higher for the CES-D-10 in the Afrikaans sample, the cutoffs identified on the CES-D-10 consistently generated higher sensitivity, specificity and PPV compared to the PHQ-9 cut-offs. Results therefore suggest that the performance of the CES-D-10 as a screening tool is on par with, if not slightly stronger than the PHQ-9.

Given that both instruments comprise of 10 items and should take the same time to administer, the authors recommend using either screening tool to assess depressive symptoms in the future. Despite the CES-D10 having slightly stronger psychometric properties than the PHQ-9 in the present study, the poorer performance of the two CES-D-10 positive affect items may lead researchers and clinicians to give preference to the PHQ-9, however.

\section{Limitations}

Limitations of the study should be noted. First, it was not possible to assess the cultural differences in the CES-D-10's performance among the Afrikaans-speaking population in the Western Cape, given the small number of non-coloured individuals recruited. The difficulty in recruiting from the white population was also noted in previous waves of NIDS, and is not specific to the present study. However, given the differences in sociodemographic and economic characteristics found across the different Afrikaans-speaking groups in this study, the exclusion of non-coloured participants from the analysis meant that the remaining Afrikaans sample was more culturally homogeneous, and stronger interpretations of the findings could be made for this specific population.

The different cut-offs identified across the three samples suggest that generalising the present findings to other linguistic groups within South Africa may not be possible. Great care was taken in the translation and back-translation of the tool, so it is unlikely that any differences found between the three samples were due to translation errors. Instead, these are likely to reflect differences in the perception and experience of depression, and in the idioms of distress used among different South African populations [38].

Second, the prevalence of depression measured by the MINI 6.0 was relatively low in the Zulu and Xhosa samples, which weakens the inferences that can be made based on the results. Nonetheless, the results corroborate previous evidence on the internal structure of the scale, suggesting that psychometric properties of the CES-D-10 in these samples are reasonably robust.

Finally, despite the sampling methodology, gender was not proportionally distributed, and samples consisted predominantly of women. Results suggest women reported higher CES-D-10 scores and were more likely to be depressed compared to men in the Afrikaans and Xhosa samples. This finding corroborates results from the SASH study suggesting that women had a higher lifetime prevalence of depression or other mood disorders in South Africa [4]. This likely inflated the overall sample and estimated population prevalence of depression reported in this study, and may have affected the performance of the CES-D-10 in relation to the MINI. However, the gender distribution were relatively consistent across the three samples, so this cannot explain the disproportion in the prevalence of major depression reported among the Zulu, Xhosa and Afrikaans samples.

\section{Conclusion}

The findings suggest that the CES-D-10 has good psychometric properties in Zulu, coloured Afrikaans and Xhosa-speaking populations, similar to those of the PHQ-9. The CES-D-10 is therefore an adequate tool to 
identify individuals at risk for depression among these populations. Given that different cut-offs were found for the three populations, the validation of the CES-D-10 in the other South African language groups may be required to identify language-specific cut-offs. Test-retest reliability was beyond the scope of this study, but would be useful for future studies to investigate the reliability of the CES$\mathrm{D}-10$ in the three languages. Through greater certainty about the validity of the CES-D-10, this study has the potential to contribute to substantial new knowledge on a range of socioeconomic predictors and consequences of depression in the unique NIDS longitudinal dataset.

\section{Endnotes}

${ }^{1}$ Budlender D (2015). Prevalence of poor mental health: Evidence from NIDS (short report).

\begin{abstract}
Abbreviations
AUROC: Area under the Receiver Operating Characteristics curve; CESD: Centre for Epidemiological Studies Depression Scale; CES-D-10: Centre for Epidemiological Studies Depression Scale - 10 item version; Cl: Confidence interval; DSM-IV: Diagnostic and Statistical Manual of Mental Disorders fourth edition; IQR: Interquartile range; MINI: Mini International Neuropsychiatric Interview; NIDS: National income dynamic study; NPV: Negative predictive value; PHQ-9: Patient Health Questionnaire - 9 item version; PPV: Positive predictive value; ROC: Receiver Operating Characteristics; SAL: Small area level; SASH: South African Stress and Health study; WHODAS: WHO Disability Assessment Schedule.
\end{abstract}

\section{Acknowledgements}

We would like to thank the Principal Investigators of the NIDS, who have been involved in designing this study and its funding. We would also like to acknowledge the fieldworkers for their hard work, as well as GeoSpace, who provided great support in developing the sampling strategy and in fieldwork management. Finally, we would like to thank Dr Sujit Rathod for his sampling and analytical support.

\section{Funding}

This work was supported by the National Income Dynamics Study (NIDS), at the University of Cape Town, South Africa. The NIDS is implemented by the Southern Africa Labour and Development Research Unit (SALDRU), and is funded by the Department of Planning, Monitoring and Evaluation (DPME). The funding body was involved in the design of the study.

\section{Availability of data and materials}

The datasets supporting the conclusions of this article are available from the corresponding author on reasonable request.

\section{Authors' contributions}

$E B$, TD and CL contributed to the design of the study. EB conducted the statistical analyses and TD oversaw data collection. EB prepared the manuscript with TD and CL's support. All authors read and approved the final manuscript.

\section{Competing interests}

There are no financial or non-financial competing interests. None of the research staff received incentives for recruiting participants or for any other purpose directly related to the study.

\section{Consent for publication}

Not applicable.

\section{Ethics approval and consent to participate}

This study was approved by the University of Cape Town's Health Sciences Faculty Human Research Ethics committee (REF: 209/2016). Consent and assent forms were translated in all three languages and completed by all participants who agreed to participate.

\section{Author details}

Alan J Flisher Centre for Public Mental Health, Department of Psychiatry and Mental Health, University of Cape Town, Office 32, Building B, 46 Sawkins Road, 7700 Rondebosch, Cape Town, South Africa. ${ }^{2}$ Centre for Global Mental Health, Institute of Psychiatry, Psychology and Neuroscience, King's College London, London, UK.

Received: 28 September 2016 Accepted: 24 December 2016

Published online: 09 January 2017

\section{References}

1. World Health Organization. The global burden of disease: 2004 update. Geneva: World Health Organization; 2008.

2. Saraceno B, Levav I, Kohn R. The public mental health significance of research on socio-economic factors in schizophrenia and major depression. World Psychiatry. 2005:4(3):181-5.

3. Lund C, De Silva M, Plagerson S, Cooper S, Chisholm D, Das J, et al. Poverty and mental disorders: breaking the cycle in low-income and middle-income countries. Lancet. 2011;378(9801):1502-14.

4. Stein DJ, Seedat S, Herman A, Moomal H, Heeringa SG, Kessler RC, Williams DR. Lifetime prevalence of psychiatric disorders in South Africa. Br J Psychiatry. 2007;192(2):112-7.

5. Seedat S, Williams DR, Herman AA, Moomal H, Williams SL, Jackson PB, et al. Mental health service use among South Africans for mood, anxiety and substance use disorders. S Afr Med J. 2009;99:346-52.

6. Kagee A, Tsai AC, Lund C, Tomlinson M. Screening for common mental disorders in low resource settings: reasons for caution and a way forward. International Health. 2012:5:11-4.

7. Radloff LS. The CES-D scale a self-report depression scale for research in the general population. Appl Psychol Meas. 1977;1(3):385-401.

8. Chishinga N, Kinyanda E, Weiss HA, Patel V, Ayles H, Seedat S. Validation of brief screening tools for depressive and alcohol use disorders among TB and HIV patients in primary care in Zambia. BMC Psychiatry. 2011;11(75). doi:10.1186/1471-244X-11-75

9. Myer L, Smit J, Roux LL, Parker S, Stein DJ, Seedat S. Common mental disorders among HIV-infected individuals in South Africa: prevalence, predictors, and validation of brief psychiatric rating scales. AIDS Patient Care STDs. 2008;22(2):147-58.

10. Andresen EM, Malmgren JA, Carter WB, Patrick DL. Screening for depression in well older adults: Evaluation of a short form of the CES-D. Am J Prev Med. 1994;10(2):77-84.

11. Irwin $\mathrm{M}$, Artin $\mathrm{KH}$, Oxman MN. Screening for depression in the older adult: criterion validity of the 10-item Center for Epidemiological Studies Depression Scale (CES-D). Arch Intern Med. 1999;159(15):1701-4.

12. Lee $A E$, Chokkanathan S. Factor structure of the 10-item CES-D scale among community dwelling older adults in Singapore. Int J Geriatr Psychiatry. 2008; 23(6):592-7.

13. Boey KW. Cross-validation of a short form of the CES-D in Chinese elderly. Int J Geriatr Psychiatry. 1999;14(8):608-17.

14. Björgvinsson T, Kertz SJ, Bigda-Peyton JS, McCoy KL, Aderka IM. Psychometric Properties of the CES-D-10 in a Psychiatric Sample. Assessment. 2013;20(4):429-36.

15. Bradley $\mathrm{KL}$, Bagnell AL, Brannen CL. Factorial validity of the Center for Epidemiological Studies Depression 10 in adolescents. Issues Ment Health Nurs. 2010;31(6):408-12

16. Cheng ST, Chan A. The center for epidemiologic studies depression scale in older Chinese: thresholds for long and short forms. Int J Geriatr Psychiatry. 2005;20(5):465-70

17. Leibbrandt M, Woolard I, de Villiers L. Methodology: Report on NIDS wave 1. In: Technical paper no1. Cape Town, South Africa: University of Cape Town; 2009.

18. Tomita A, Burns JK. A multilevel analysis of association between neighborhood social capital and depression: evidence from the first South African National Income Dynamics Study. J Affect Disord. 2013;144(1-2):101-5.

19. Meffert SM, McCulloch CE, Neylan TC, Gandhi M, Lund C. Increase of perceived frequency of neighborhood domestic violence is associated with increase of women's depression symptoms in a nationally representative longitudinal study in South Africa. Soc Sci Med. 2015;131:89-97.

20. Ardington $C$, Case A. Interactions between mental health and socioeconomic status in the South African national income dynamics study. 
Tydskrif vir studies in ekonomie en ekonometrie = J Studies Econ Econometrics. 2010;34(3):69.

21. Tomita A, Burns JK. Depression, disability and functional status among community-dwelling older adults in South Africa: evidence from the first South African National Income Dynamics Study. Int I Geriatr Psychiatry. 2013;28:1270-9.

22. Tomita A, Labys CA, Burns JK. The relationship between immigration and depression in South Africa: evidence from the first South African National Income Dynamics Study. J Immigr Minor Health. 2014;16(6):1062-8.

23. Tomita A, Labys CA, Burns JK. A multilevel analysis of the relationship between neighborhood social disorder and depressive symptoms: evidence from the South African National Income Dynamics Study. Am J Orthopsychiatry. 2015;85(1):56-62.

24. Tomita A, Labys CA, Burns JK. Depressive Symptoms Prior to Pregnancy and Infant Low Birth Weight in South Africa. Matern Child Health J. 2015;19(10):2179-86

25. Kroenke K, Spitzer RL. The PHQ-9: a new depression diagnostic and severity measure. Psychiatr Ann. 2002;32(9):1-7.

26. Bhana A, Rathod SD, Selohilwe O, Kathree T, Petersen I. The validity of the Patient Health Questionnaire for screening depression in chronic care patients in primary health care in South Africa. BMC Psychiatry. 2015;15(1)

27. Cholera R, Gaynes BN, Pence BW, Bassett J, Qangule N, Macphail C, et al. Validity of the patient health questionnaire-9 to screen for depression in a high-HIV burden primary healthcare clinic in Johannesburg South Africa. J Affect Disord. 2014;167:160-6.

28. Statistics South Africa. Census 2011: Census in brief. Pretoria: Statistics South Africa; 2012.

29. Sheehan DV, Lecrubier Y, Sheehan KH, Amorim P, Janavs J, Weiller E, et al. The Mini-International Neuropsychiatric Interview (MINI): the development and validation of a structured diagnostic psychiatric interview for DSM-IV and ICD-10. J Clin Psychiatry. 1998;59:22-33.

30. Manea L, Gilbody S, McMillan D. Optimal cut-off score for diagnosing depression with the Patient Health Questionnaire (PHQ-9): a meta-analysis. Can Med Assoc J. 2012;184(3):E191-6.

31. Lozano R, Naghavi M, Foreman K, Lim S, Shibuya K, Aboyans V, et al. Global and regional mortality from 235 causes of death for 20 age groups in 1990 and 2010: a systematic analysis for the Global Burden of Disease Study 2010. Lancet. 2013;380(9859):2095-128.

32. Murray CJ, Ezzati M, Flaxman AD, Lim S, Lozano R, Michaud C, et al. GBD 2010: a multi-investigator collaboration for global comparative descriptive epidemiology. Lancet. 2013;380(9859):2055-8.

33. Peltzer K, Phaswana-Mafuya N. Levels of ability and functioning of persons living with HIV and AIDS using the WHO DAS II in a South African context. J Soc Dev Afr. 2008:23(2):33-53.

34. Üstün TB. Measuring health and disability: manual for WHO disability assessment schedule WHODAS 2.0. Geneva: World Health Organization; 2010.

35. DeLong ER, DeLong DM, Clarke-Pearson DL. Comparing the areas under two or more correlated receiver operating characteristic curves: a nonparametric approach. Biometrics. 1988;44:837-45.

36. Williams DR, Herman A, Stein DJ, Heeringa SG, Jackson PB, Moomal H, Kessler RC. Twelve-month mental disorders in South Africa: prevalence, service use and demographic correlates in the population-based South African Stress and Health Study. Psychol Med. 2008;38(2):211-20.

37. Fan J, Upadhye S, Worster A. Understanding receiver operating characteristic (ROC) curves. Can Assoc Emerg Physicians. 2006;8(01):19-20.

38. Patel V. Explanatory models of mental illness in sub-Saharan Africa. Soc Sci Med. 1995;40(9):1291-8.

\section{Submit your next manuscript to BioMed Central and we will help you at every step:}

- We accept pre-submission inquiries

- Our selector tool helps you to find the most relevant journal

- We provide round the clock customer support

- Convenient online submission

- Thorough peer review

- Inclusion in PubMed and all major indexing services

- Maximum visibility for your research

Submit your manuscript at www.biomedcentral.com/submit

) Biomed Central 